\title{
Disadvantageous closure of the interventricular communication in double outlet right ventricle
}

\author{
L M GERLIS, D F DICKINSON, R H ANDERSON \\ From the Departments of Pathology and Paediatric Cardiology, Killingbeck Hospital, Leeds; and the Cardiothoracic \\ Institute, Brompton Hospital, London
}

SUMmARY A double outlet right ventricle was diagnosed in a 10 week old infant, in whom the ventricular septum was intact at the time of presentation. A large aneurysm of a membranous septal remnant was present, and this appears to be the first recorded instance of closure of a malalignment ventricular septal defect by such a mechanism.

It has been asserted that a ventricular septal defect is universally present in double outlet right ventricle and that its presence is mandatory for the survival of the patient. ${ }^{1}$ Certainly, the position of the defect is considered to be the most important basis for the classification of the various types. ${ }^{23}$ Yet 16 cases of double outlet right ventricle have been reported with an intact ventricular septum. In 12 of these there was atresia or stenosis of the mitral valve and either an absent left ventricle as judged by gross examination or no details of ventricular morphology. ${ }^{4-9}$ Four cases had two well formed ventricles and an intact ventricular septum..$^{10-13}$

We report a further case of double outlet right ventricle, in which the only communication between the two ventricles was iatrogenic.

\section{Case report}

A 10 week old baby was referred by her general practitioner because of failure to thrive. The electrocardiogram showed a superiorly orientated $P$ wave axis with increased precordial voltages. Chest $x$ ray films showed dextrocardia with cardiomegaly and pulmonary venous congestion. The bronchial anatomy was not clearly defined. Cross sectional echocardiography showed the presence of two atria, each connected to a separate ventricle, with both great arteries originating from the left sided ventricle. A septal defect was not identified. Cardiac catheterisation was performed from the right femoral vein, and a catheter was

Requests for reprints to Dr L M Gerlis, Killingbeck Hospital, York Road, Leeds LS14 6UQ. advanced along the azygos vein to a left superior caval vein and then to the left sided atrium and left sided ventricle. It proved impossible to manipulate the catheter through the right sided atrioventricular valve. A catheter introduced from the right femoral artery was therefore passed retrogradely across the aortic valve and into the left sided ventricle. With further manipulation and the use of a guide wire the right sided ventricle was also entered. An injection in this ventricle showed a bulging of the septum (Fig. 1). Angiography of the left sided ventricle showed it to be of morphologically right pattern with both great arteries arising from it, the pulmonary trunk lying anteriorly. The cardiac catheterisation was well tolerated with no complications, but shortly afterwards the infant developed an acute massive upper gastrointestinal haemorrhage and died.

At necropsy, the haemorrhage was shown to have resulted from a large duodenal ulcer which had extended into the head of the pancreas. There was complete mirror image arrangement of the abdominal viscera (Fig. 2a). The lungs showed left isomerism in that each was bilobed and each had a long main hyparterial bronchus. The heart was situated in the right hemithorax with its apex directed to the right. Each atrial chamber was of morphologically left type (left atrial isomerism).

Visceral arrangements and venous connexions are shown in Fig. 2a and the arrangement of the ventricular mass in Fig. 2b. There was an ambiguous atrioventricular connexion to a left hand pattern ventricle ( 1 loop) via two atrioventricular valves. Both great arteries originated from the left sided morphologically right ventricle (Fig. 2b). There was no obvious ventricular septal defect, but a bulge was seen in the left sided right ventricle between the limbs of the sep- 


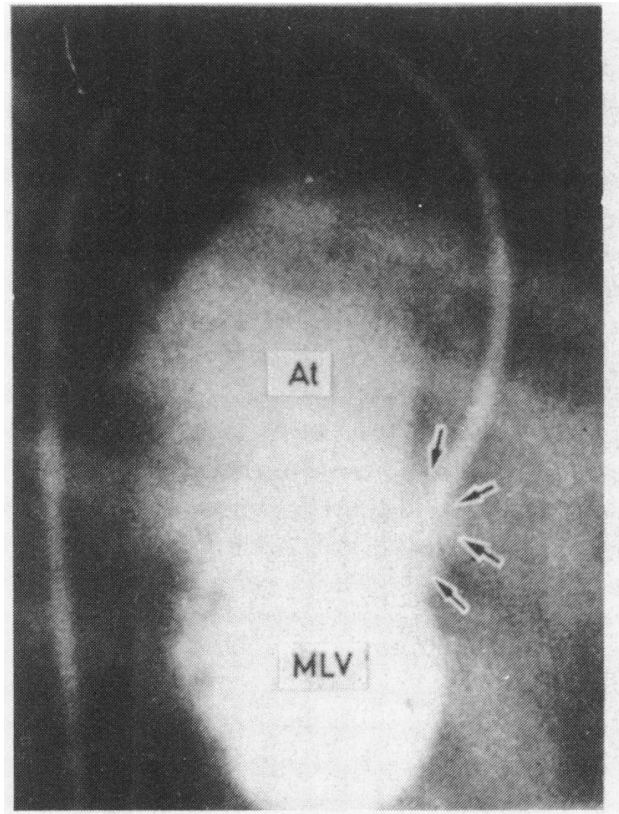

Fig. 1 Angiocardiogram of the right side of the heart via a catheter passed retrogradely through the aorta into the left sided ventricle and through the membranous septum aneurysm (arrow). The ventricle has the appearance of a morphological left ventricle $(M L V)$. There is reflux into the atrium $(A t)$ but no evident interventricular shunt. tomarginal trabecula (Fig. 3a). This was due to an aneurysmal enlargement of a remnant of the interventricular membranous septum which blocked a preexisting subaortic ventricular septal defect. The pulmonary and aortic valves were normal.

In view of the angiographic findings the specimen was critically re-examined. A cardiac catheter, identical to that used in the angiographic examination, was passed into the aorta and downwards through the aortic valve. On manipulation the tip showed and then penetrated a minute ragged tear, $2 \mathrm{~mm}$ long, near the base of the anterior tricuspid leaflet, and as it advanced it penetrated a similar tear in the adjacent anterior portion of an aneurysmal remnant of the interventricular membranous septum to enter the right sided morphologically left ventricle (Fig. 3b). The final diagnosis was left atrial isomerism with ambiguous atrioventricular connexion and double outlet right ventricle (quasi inversus-concordantdouble outlet right ventricle) ${ }^{14}$ together with an intact ventricular septum due to closure of a pre-existing defect by an aneurysmal membranous septum.

\section{Discussion}

The essence of double outlet right ventricle is malalignment between the infundibular (outlet) septum and the rest of the ventricular septum, which is formed only by inlet, trabecular, and membranous
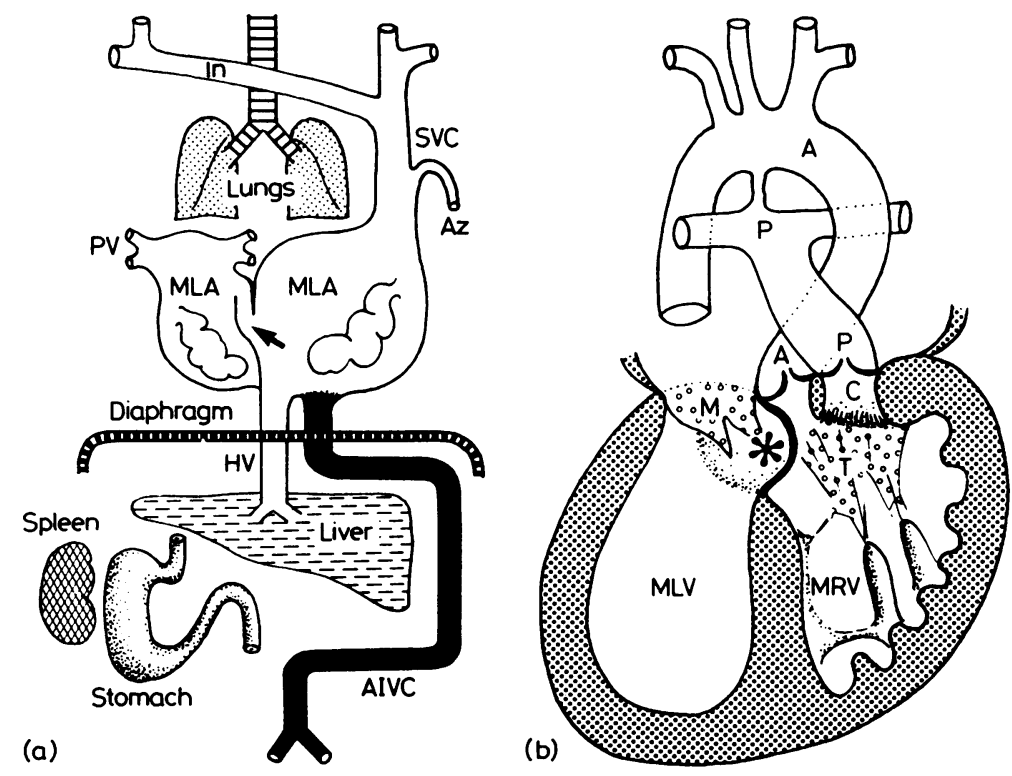

Fig. 2 Diagrams showing (a) the left isomerism morphology of the viscera and the atria: $A I V C$, abnormal inferior vena cava; $A z$, azygos vein; $H V$, hepatic vein; In, innominate vein; $M L A$, morphological left atrium; $P V$, pulmonary veins; SVC, superior vena cava; and (b) the morphology of the ventricles and great arteries: $A$, aorta; $C$, crista supraventricularis; $P$, pulmonary artery; $M$, mitral valve (round stipple); $M L V$, morphological left ventricle; $M R V$, morphological right ventricle; $T$, tricuspid valve (round stipple); *, membranous septum aneurysm. 


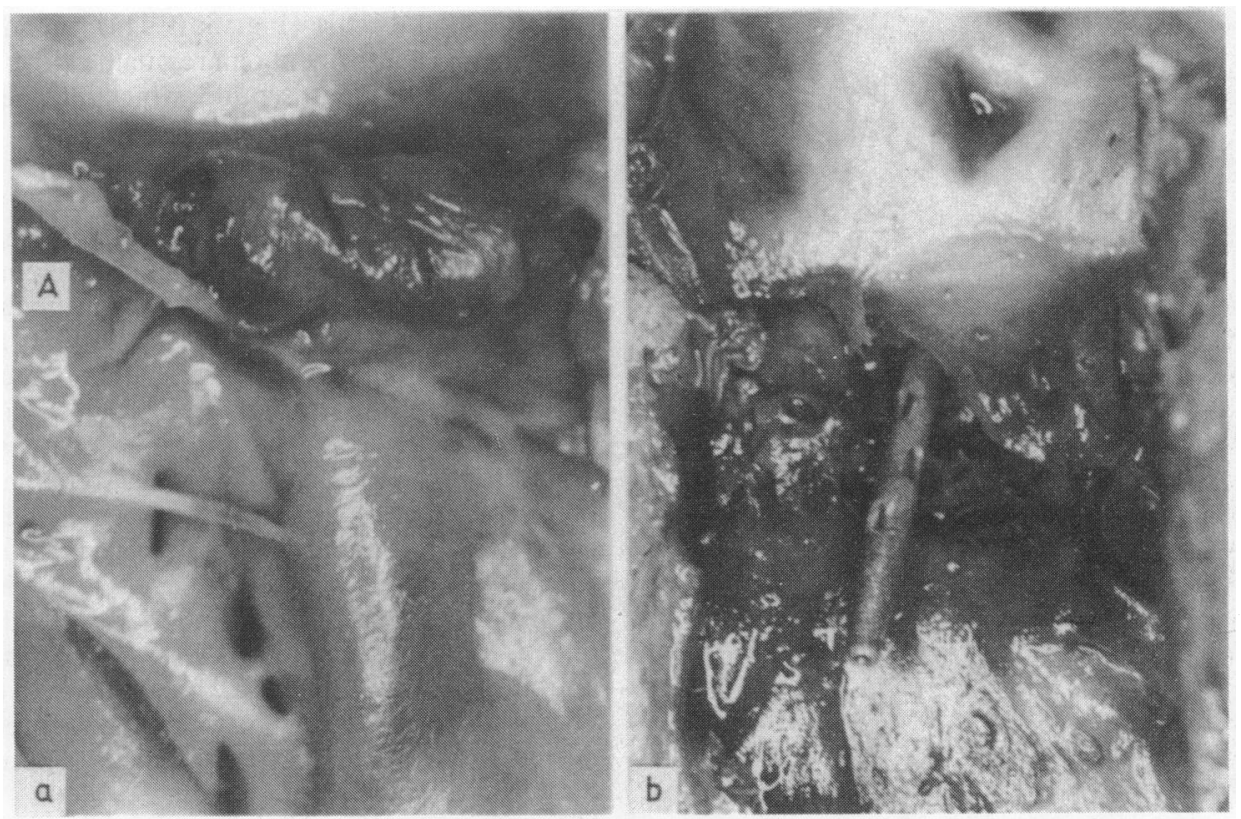

Fig. 3 Morphological view of the membranous septum aneurysm showing (a) the junction with the muscular septum and the position of the aortic orifice $(A)$, and $(b)$ the entry of the catheter into the right sided ventricle after piercing the aneurysm.

portions. Closure, if it occurs, must always be by an abnormal mechanism.

A ventricular septal defect is not, as is generally maintained, 161516 invariably the only outlet from the left ventricle. An incompetent mitral valve will permit egress of blood during left ventricular systole. In our case, the dysplastic mitral valve was deeply cleft and was clearly incompetent at angiography.

The mechanism of ventricular closure in these cases merits special attention. Wilcox et al ${ }^{12}$ proposed that closure of a pre-existing subaortic ventricular septal defect was the most likely explanation for all hearts of this unusual type, but they did not speculate on the manner of such closure. In a similar case, ${ }^{13}$ the ventricular septal defect was said to be closed by accessory fibrous tissue. Only one instance of histological examination of such a "closed ventricular septal defect" has been recorded, and the changes were attributed to an embryonic inflammatory process. ${ }^{8}$ Closure of the defect by involvement of an atrioventricular valve has been reported in two cases. ${ }^{1011}$

So called "aneurysms of the membranous septum" are sometimes associated with small isolated ventricular septal defects and may be a mechanism of spontaneous closure. ${ }^{1718}$ This was the mechanism in our case and is the first reported instance of this association with a double outlet right ventricle.

LMG is supported by the National Heart Research Fund, and RHA by the Joseph Levy Foundation together with the British Heart Foundation.

\section{References}

1 Neufeld HN, du Shane JW, Wood EH, Kirklin JW, Edwards JE. Origin of both great vessels from the right ventricle. (I) Without pulmonary stenosis. Circulation 1961; 23: 399-412.

2 Neufeld HN, Lucas RV Jr, Lester RG, Adams P Jr, Anderson RC, Edwards JE. Origin of both great vessels from the right ventricle without pulmonary stenosis. $\mathrm{Br}$ Heart f 1962; 24: 393-408.

3 Becker A, Anderson RH. Pathology of congenital heart disease. London: Butterworth, 1981: 297.

4 Lev M, Bharati S. Double outlet right ventricle. Association with other cardiovascular anomalies. Arch Pathol 1973; 95: 117-22.

5 MacMahon HE, Lipa M. Double-outlet right ventricle with intact interventricular septum. Circulation 1964; 30: 745-8.

6 Ainger LE. Double outlet right ventricle: intact ventricular septum, mitral stenosis, and blind left ventricle. Am Hearn f 1965; 70: 521-5.

7 Davachi F, Moller JH, Edwards JE. Origin of both great vessels from right ventricle with intact ventricular septum. Am Heart f 1968; 75: 790-4.

8 Oppenheimer-Dekker A, Gittenberger-de Groot AC. Double-outlet right ventricle without ventricular septal defect. A challenge to the embryologist? Microscopic investigation. Zeitschrift für Anatomie und Entwicklungsgeschichte 1971; 134: 243-54. 
9 Sridaromont S, Feldt RH, Ritter DG, Davis GD, Edwards JE. Double outlet right ventricle. Hemodynamic and anatomic correlations. Am $\mathcal{f}$ Cardiol 1976; 38: 85-94.

10 Edwards JE, James JW, du Shane JW. Congenital malformation of the heart. Origin of transposed great vessels from the right ventricle associated with atresia of the left ventricular outlet, double orifice of the mitral valve and single coronary artery. Laboratory Investigation 1952; 1: 197-207.

11 Rao PS, Sissman NJ. Spontaneous closure of physiologically advantageous ventricular septal defects. Circulation 1971; 43: 83-90.

12 Wilcox BR, Ho SY, Macartney FJ, Becker AE, Gerlis LM, Anderson RH. Surgical anatomy of double outlet right ventricle with situs solitus and atrioventricular concordance. F Thorac Cardiovasc Surg 1981; 82: 405-17.
13 Marino B, Loperfido F, Sardi CS. Spontaneous closure of ventricular septal defect in a case of double outlet right ventricle. $B r$ Heart $f$ 1983; 49: 608-11.

14 Macartney FJ, Zuberbuhler JR, Anderson RH. Morphological considerations pertaining to recognition of atrial isomerism. Consequences for sequential chamber localisation. Br Heart f 1980; 44: 657-67.

15 Shinebourne EA, Anderson RH. Current paediatric cardiology. Oxford: Oxford University Press, 1980: 190.

16 Cheng TO. Double outlet right ventricle. Am f Med 1962; 32: 637-44.

17 Neufeld HN, Titus JL, du Shane JW, Burchell HB, Edwards JE. Isolated ventricular septal defect of the persistent common atrio-ventricular canal type. Circulation 1961; 23: 685-96.

18 Jain AC, Rosenthal R. Aneurysm of the membranous ventricular septum. Br Heart f 1967; 29: 60-3. 